\title{
Antibacterial, Antihemolytic, Cytotoxic, Anticancer, and Antileishmanial Effects of Ajuga bracteosa Transgenic Plants
}

\author{
Samina Rubnawaz ${ }^{1, *(\mathbb{D}}$, Mohammad K. Okla ${ }^{2}$, Nosheen Akhtar $\left.{ }^{3}{ }^{(}\right)$, Imdad Ullah Khan ${ }^{4} \mathbb{D}^{\circ}$, \\ Muhammad Zeeshan Bhatti ${ }^{3}{ }^{(D}$, Hong-Quan Duong ${ }^{5}$, Mohamed A. El-Tayeb ${ }^{2}$, Yahaya B. Elbadawi ${ }^{2}$, \\ Khalid S. Almaary ${ }^{2}$, Ihab M. Moussa ${ }^{2}$, Zahid Khurshid Abbas ${ }^{6}$ and Bushra Mirza ${ }^{1}$ D \\ 1 Department of Biochemistry, Quaid i Azam University, Islamabad 45320, Pakistan; bushramirza@qau.edu.pk \\ 2 Botany and Microbiology Department, College of Science, King Saud University, Riyadh 11451, Saudi Arabia; \\ malokla@ksu.edu.sa (M.K.O.); mali5@ksu.edu.sa (M.A.E.-T.); yalbadawi@ksu.edu.sa (Y.B.E.); \\ Kalmaary@ksu.edu.sa (K.S.A.); imoussa1@ksu.edu.sa (I.M.M.) \\ 3 Department of Biological Sciences, National University of Medical Sciences, Rawalpindi 46000, Pakistan; \\ nosheenakhtar@numspak.edu.pk (N.A.); zeeshan.bhatti@numspak.edu.pk (M.Z.B.) \\ 4 Department of Biotechnology, Abdul Wali Khan University, Mardan 23200, Pakistan; ik16092@gmail.com \\ 5 Laboratory Center, Hanoi University of Public Health, Hanoi 100000, Vietnam; dhq@huph.edu.vn \\ 6 Biology Department, College of Science, Tabuk University, Tabuk 71491, Saudi Arabia; Zahid104@yahoo.com \\ * Correspondence: samina.r.nawaz@gmail.com
}

Citation: Rubnawaz, S.; Okla, M.K.; Akhtar, N.; Khan, I.U.; Bhatti, M.Z.; Duong, H.-Q.; El-Tayeb, M.A.; Elbadawi, Y.B.; Almaary, K.S.; Moussa, I.M.; et al. Antibacterial, Antihemolytic, Cytotoxic, Anticancer, and Antileishmanial Effects of Ajuga bracteosa Transgenic Plants. Plants 2021, 10, 1894. https://doi.org/ 10.3390/plants10091894

Academic Editors: Yun-Soo Seo and Joong-Sun Kim

Received: 16 August 2021

Accepted: 8 September 2021

Published: 13 September 2021

Publisher's Note: MDPI stays neutral with regard to jurisdictional claims in published maps and institutional affiliations.

Copyright: (c) 2021 by the authors. Licensee MDPI, Basel, Switzerland. This article is an open access article distributed under the terms and conditions of the Creative Commons Attribution (CC BY) license (https:/ / creativecommons.org/licenses/by/ $4.0 /)$.

\begin{abstract}
Herbal and traditional medicines can play a pivotal role in combating cancer and neglected tropical diseases. Ajuga bracteosa, family Lamiaceae, is an important medicinal plant. The genetic transformation of A. bracteosa with rol genes of Agrobacterium rhizogenes further enhances its metabolic content. This study aimed at undertaking the molecular, phytochemical, and in vitro biological analysis of $A$. bracteosa extracts. We transformed the A. bracteosa plant with rol genes and raised the regenerants from the hairy roots. Transgenic integration and expression of rolB were confirmed by conventional polymerase chain reaction (PCR) and qPCR analysis. The methanol: chloroform crude extracts of wild-type plants and transgenic regenerants were screened for in vitro antibacterial, antihemolytic, cytotoxic, anticancer, and leishmanial activity. Among all plants, transgenic line 3 (ABRL3) showed the highest expression of the rolB gene. Fourier transform infra-red (FTIR) analysis confirmed the enhanced number of functional groups of active compounds in all transgenic lines. Moreover, ABRL3 exhibited the highest antibacterial activity, minimum hemolytic activity $\left(\mathrm{CC}_{50}=7293.05 \pm 7 \mu \mathrm{g} / \mathrm{mL}\right)$ and maximum antileishmanial activity $\left(\mathrm{IC}_{50}\right.$ of $\left.56.16 \pm 2 \mu \mathrm{g} / \mathrm{mL}\right)$. ABRL1 demonstrated the most prominent brine shrimp cytotoxicity ( $\mathrm{LD}_{50} 39.6 \pm 4 \mu \mathrm{g} / \mathrm{mL}$ ). ABRL3 was most effective against various human cancer cell lines with an $\mathrm{IC}_{50}$ of $57.1 \pm 2.2 \mu \mathrm{g} / \mathrm{mL}$, $46.2 \pm 1.1 \mu \mathrm{g} / \mathrm{mL}, 72.4 \pm 1.3 \mu \mathrm{g} / \mathrm{mL}, 73.3 \pm 2.1 \mu \mathrm{g} / \mathrm{mL}, 98.7 \pm 1.6 \mu \mathrm{g} / \mathrm{mL}$, and $97.1 \pm 2.5 \mu \mathrm{g} / \mathrm{mL}$ against HepG2, LM3, A549, HT29, MCF-7, and MDA-MB-231, respectively. Overall, these transgenic extracts may offer a cheaper therapeutic source than the more expensive synthetic drugs.
\end{abstract}

Keywords: Ajuga bracteosa; qPCR; FTIR; principal component analysis; antibacterial; antihemolytic; brine shrimp cytotoxicity; anticancer; cell lines; antileishmanial activity

\section{Introduction}

In recent years, the emergence of bacterial resistance against the 3rd and 4th generation beta-lactam drugs is a big challenge. To counter this, several new drugs have been developed, and medicinal plants have also been acknowledged as a potential source of therapeutic compounds for drug design. Despite these big strides, bacterial resistance to many antimicrobials is still on the increase [1]. More recently, numerous studies have been carried out on the antibacterial activities of phenolic-rich plant extracts. However, due to the enormous wealth of plant species and phytoconstituents, the level of their investigation is still insufficient [2]. Additionally, no antimicrobial with economic potential has yet been 
discovered from plants. Therefore, further screening of plants could facilitate the discovery of suitable antimicrobial drugs.

Many studies ascertain the potential health benefits of plant polyphenols as naturally occurring antioxidants [3]. The human erythrocyte has been proposed as a valuable in vitro model to study the oxidant/antioxidant interaction. The erythrocyte membrane is extremely susceptible to free-radical-mediated peroxidation due to its high content of polyunsaturated fatty acids, which might be counteracted by antioxidants [4]. Thus, hemolysis is an important indicator of free-radical-induced membrane damage to the human red blood cells (RBCs) [5].

Cancer and leishmaniasis are major health problems, and the struggle to combat these disorders is a huge challenge to mankind [6]. Cancer is the second leading cause of mortality and morbidity after cardiovascular disease worldwide. The World Health Organization (WHO) has estimated that approximately 11 million people are diagnosed with cancer every year, causing 7 million deaths per year [7]. According to the latest report, 8.2 million new cases of cancer and 5.2 million deaths are reported in Asia. Most people are affected by breast cancer (13.5\%), lung cancer ( $8 \%)$, and colorectal cancer (6.2\%) [8]. Despite the huge amount spent on synthetic drug development, still many difficulties persist in cancer therapeutics. Therefore, considerable effort has centered around plants for identifying cost-effective and target-oriented chemopreventive agents [9].

Brine shrimp cytotoxicity is a simple and inexpensive bench-top bioassay used for preliminary determination of cytotoxicity of natural substances [10]. The strong correlation between the brine shrimp assay and in vitro growth inhibition of human cancer cell lines demonstrated by the National Cancer Institute (NCI, USA) is significant because it shows the value of this bioassay as a pre-screening tool for antitumor drug research. Thus, this method can be used to evaluate the toxicity of plant samples for predicting cytotoxic concentration range and cytotoxicity validation in cancer cell lines [11]. Leishmaniasis is an endemic yet neglected disease caused by multiple protozoan parasite species of the genus Leishmania. It is transmitted to humans by the bite of infected female sandflies in tropical and subtropical areas. This devastating parasitic infection has various clinical manifestations, including cutaneous leishmaniasis (CL), visceral leishmaniasis (VL), and mucocutaneous leishmaniasis (ML) [12]. According to WHO, 85\% of CL cases are found in 10 countries, including Pakistan, while 1.7 billion people in around 98 countries are at risk of developing leishmaniasis [13]. It is speculated that leishmaniasis might contribute to carcinogenesis in immunocompromised patients and vice versa. However, the complete etiology of the underlying mechanism is not fully understood [14]. Currently available anti-parasitic drugs (pentavalent antimonials) have several disadvantages in terms of high cost, toxicity, poor prognosis, and serious side effects [15].

Natural products, particularly plants, have been used for the treatment of infectious diseases and malignancies since prehistoric times. Ajuga bracteosa Wall. ex Benth. is one such perennial herbal plant growing wild in hilly areas from Kashmir to Pakistan. Traditionally, root extracts of $A$. bracteosa are used for the treatment of diarrhea, dysentery, and inflammatory disorders, whereas the decoction of leaves and bark is used for cancer, sore throat, cough, pneumonia, and other respiratory issues $[16,17]$. Furthermore, this plant is also used to treat hypoglycemia, jaundice, protozoan infection, and gastric ulcer [18]. The holistic medicinal value of $A$. bracteos $a$ is ascribed to the presence of phenolics, flavonoids, terpenoids, saponins, tannins, and other metabolites [19].

Unfortunately, the amount of these medicinally important metabolites is very low in naturally growing A. bracteosa. However, genetic transformation of $A$. bracteosa with root oncogenic loci $(\mathrm{rol})$ genes, found in the T-DNA of Agrobacterium rhizogenes, offers a promising approach to enhance the production of secondary metabolites [20]. Among all $\mathrm{rol}$ genes, $\mathrm{rolB}$ is the most powerful inducer of secondary metabolism following an unknown mechanism. The rolB gene not only induces the large-scale production of therapeutically important products in plants but also positively regulates photosynthesis and increases plant tolerance against biotic and abiotic stresses, thus, improving plant survival [21]. 
Keeping this in mind, the current study was designed to analyze the expression of rolB genes in $A$. bracteosa plants regenerated from rolABC transformed hairy roots. Furthermore, the effect of rol genes on the production of secondary metabolites and various biological activities of $A$. bracteosa plants was also investigated.

A variety of techniques can be used to detect phytochemical entities of medicinal plants, e.g., spectroscopy. Fourier-transform infrared (FTIR) spectroscopy is a simple, cheap, and rapid tool to characterize functional groups and chemical bonds in biological samples [22]. FTIR coupled with principal component analysis (PCA), a multivariant technique, describes a correlation between different species and multiple samples of the same species based on their spectral profiles [23].

In the present study, genetic integration of the rolB gene in A. bracteosa was validated by conventional polymerase chain reaction (PCR), and its real-time expression was checked by quantitative real-time PCR (qPCR). FTIR coupled PCA was applied to identify medicinally important functional groups in A. bracteosa. This study also assessed the antibacterial, antihemolytic, cytotoxic activity against brine shrimps and antileishmanial activity of crude extracts. The dose-dependent anticancer effect of $A$. bracteos $a$ against human liver cancer cell lines (HepG2, LM3), human colon cancer cell line (HT-29), human lung cancer cell line (A549), and human breast cancer cell lines (MCF-7, MDA-MB-231) were also evaluated.

\section{Results}

In this study, three independent transgenic lines of intact Ajuga bracteosa plants (ABRL1-3) were successfully regenerated from transgenic hairy roots. These regenerated plants presented distinct morphological variability from untransformed tissue cultured wild-type (WT) A. bracteosa plants. WT plants were tall and soft in texture with prominent nodal regions, whereas all transgenic regenerants were abnormally dwarf with short internodes and bushy appearance. Leaves were wrinkled and visibly lacking midrib.

\subsection{Molecular Analyses of Ajuga bracteosa Plants}

PCR performed with rolB primers showed the presence of a $779 \mathrm{bp}$ amplicon in regenerated plantlets, as shown in Figure 1. Similar amplified products were obtained from LBA-9402 plasmid DNA. No such band was found in WT plants.

\section{ABRL1 ABRL2 ABRL3 P WT}

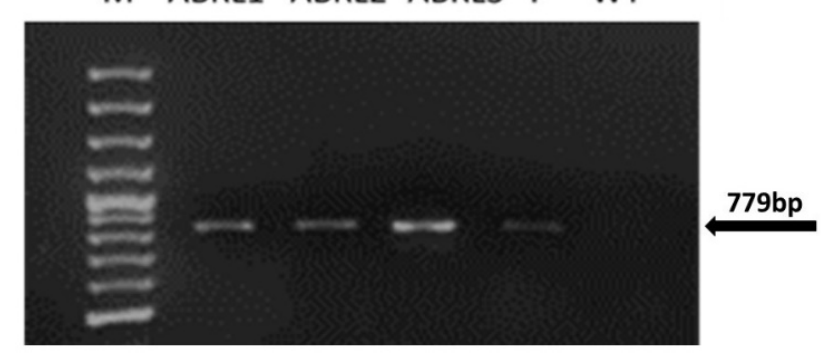

Figure 1. PCR amplification with rolB specific primers. Lane $M$ represents 100 bp DNA marker (Fermentas); ABRL1-3 are transgenic lines of A. bracteosa; WT stands for wild-type tissue cultured plants; $P$ corresponds to plasmid DNA.

The expression of the rolB gene in wild type and transgenic regenerants of $A$. bracteosa was assessed by qPCR. We found no expression of the rolB gene in the WT plants. Overall, transgenic line 3 (ABRL3) showed the most significant expression $(* *<0.01)$ of the rolB gene, followed by transgenic line 2 (ABRL2) and transgenic line 1 (ABRL1), as given in Figure 2. 


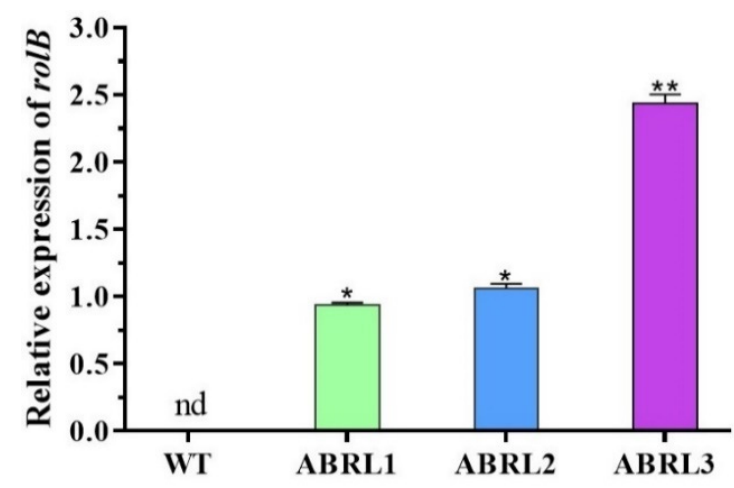

Figure 2. Relative expression of rolB gene in wild type and three independent transgenic lines of $A$. bracteosa. The expression level was normalized with the $\beta$-actin and $18 \mathrm{~s}$ reference genes. Data are expressed as mean \pm S.D. $\left({ }^{* *} p<0.01,{ }^{*} p<0.05\right)$, nd $=$ not detected.

\subsection{FTIR Coupled with $P C A$}

FTIR analysis was used to determine the functional groups of active compounds present in both transformed and wild-type plant extracts of $A$. bracteosa. The wavelength of light absorbed is a salient feature of the chemical bonds, as can be seen in the annotated spectra (Figure 3a-d).
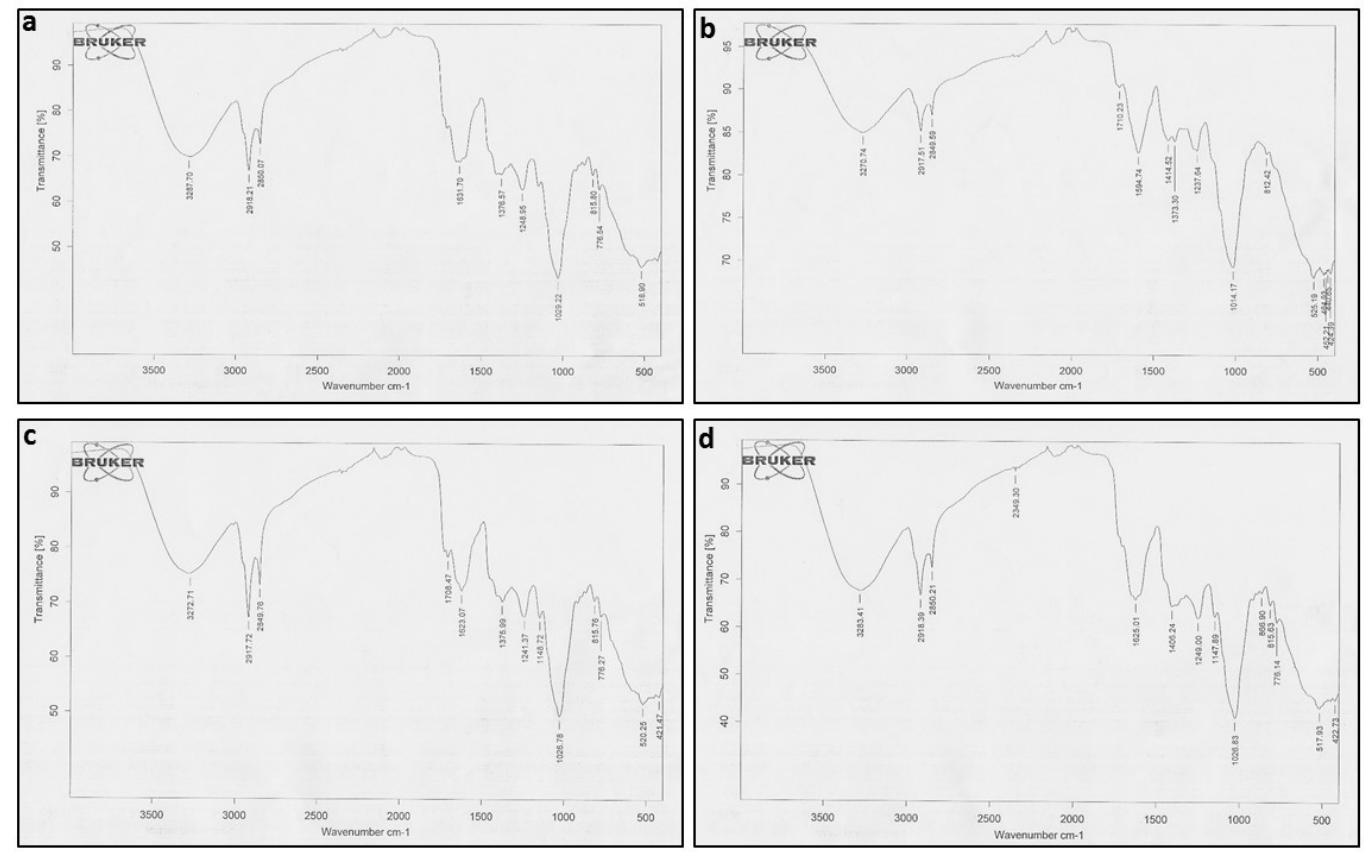

Figure 3. FTIR spectra of different lines of Ajuga bracteosa (a) WT (b) ABRL1 (c) ABRL2 (d) ABRL3.

These spectra revealed that ABRL1 has 11 major peaks between 525.19 and $3270.74 \mathrm{~nm}$, ABRL2 has 12 (520.25-3272.71 nm), ABRL3 has 13 (517.93-3283.41 nm), while WT has 10 peaks $(518.90-3287.70 \mathrm{~nm})$. All the crude extracts represented somewhat similar functional groups except Thiol/mercaptan (S-H) at $2349.30 \mathrm{~nm}$, only found in ABRL3 and Ether group found in ABRL2 and ABRL3. Peak values of absorption spectra, along with their expected functional groups, are given in Table 1. 
Table 1. FTIR analysis and functional groups.

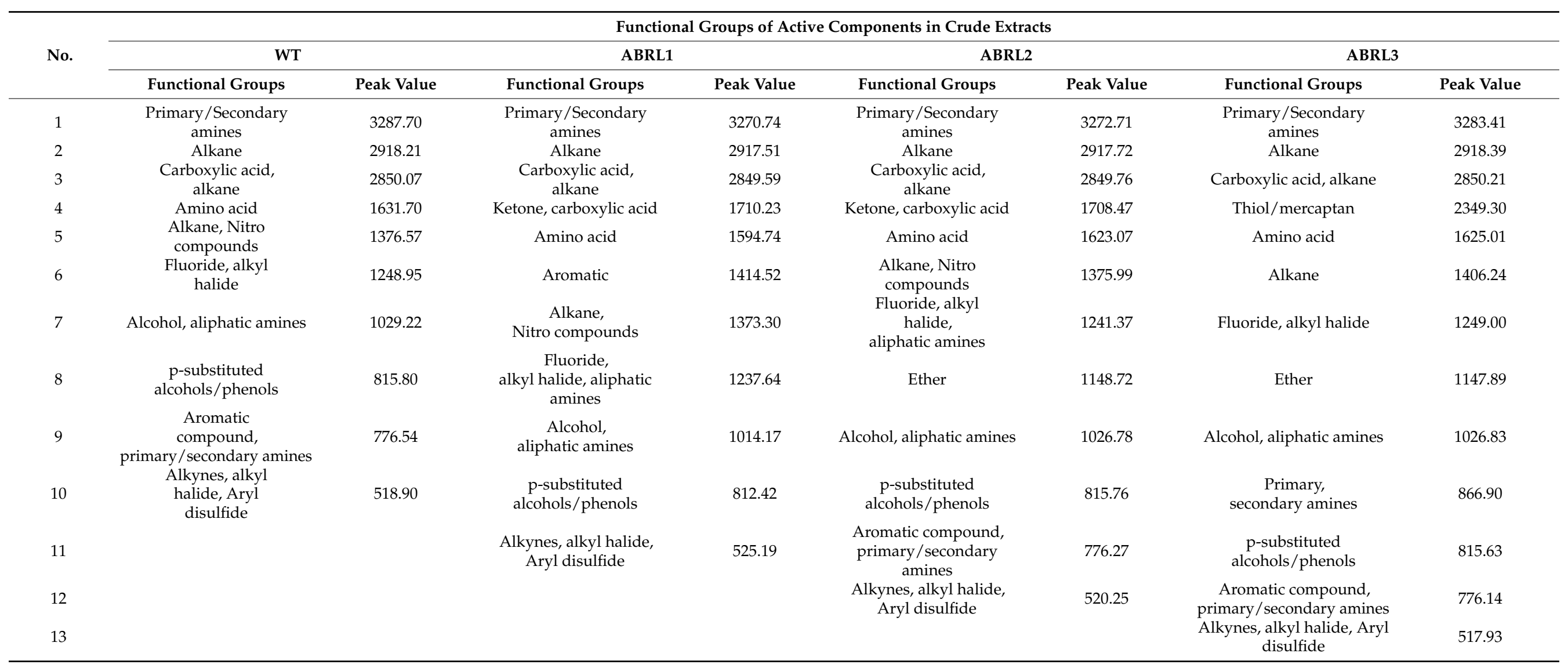


The multivariate statistical analysis technique, PCA, successfully explains the variability in each data set. In the current study, PCA was used to evaluate the extent of similarities or differences between multiple plant samples based on the number of detected functional groups. Here, PCA recognized three significant components: principal component 1 (PC1) explained $61.62 \%$ of the variance, while principal component 2 (PC2) had a variation of $25.99 \%$. Principal component 3 (PC3) showed 12.38\% of the variability. The combination of PC1 and PC2, as well as PC1 and PC3, categorized the four used plant samples into distinctive regions (Figure $4 \mathrm{a}, \mathrm{c}$ ). This confirmed that significant diversity of functional groups did exist in all samples. A biplot marked a clear relationship among different lines of $A$. bracteosa and their functional groups (Figure $4 \mathrm{~b}, \mathrm{~d}$ ).
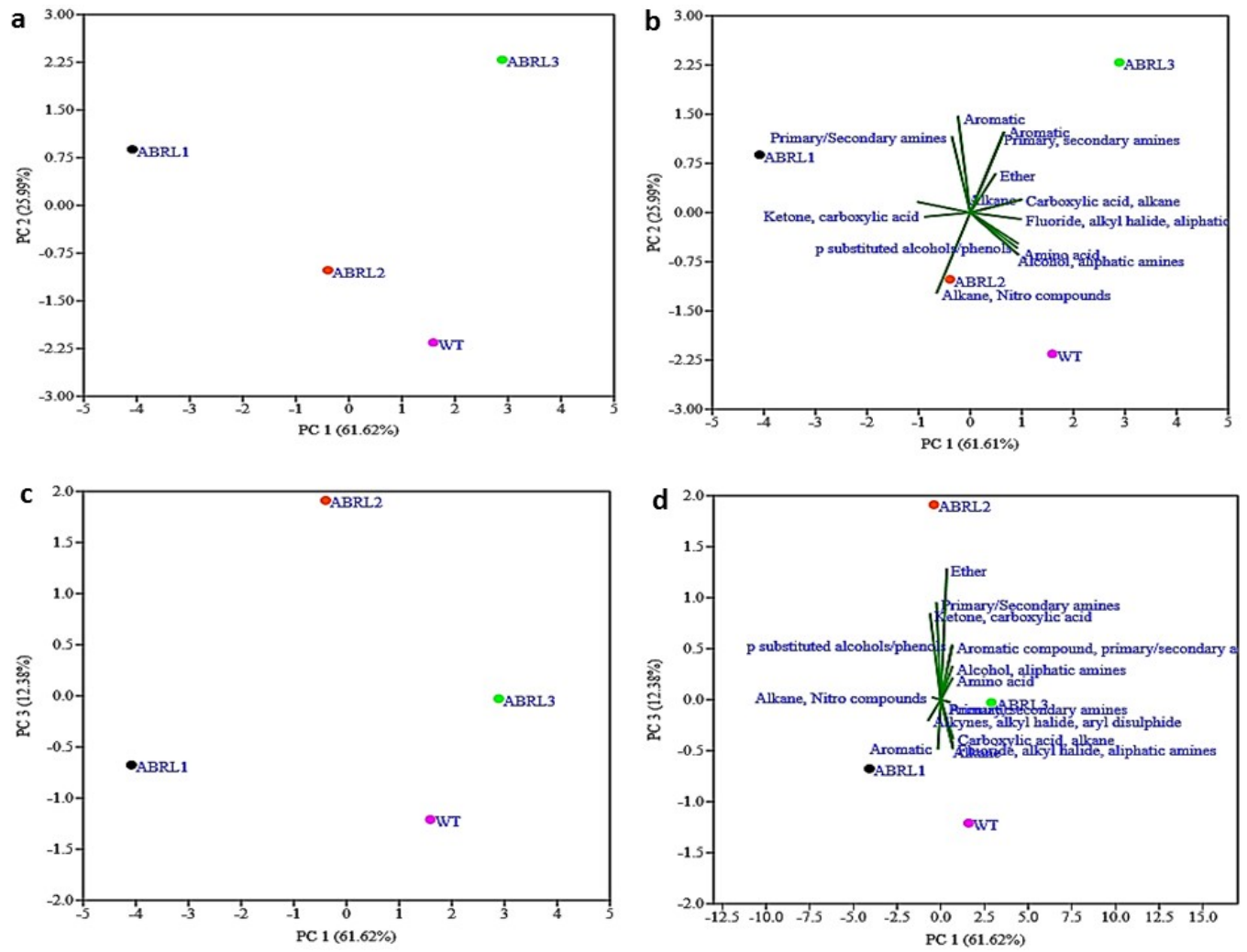

Figure 4. Principal component analysis (PCA) of functional groups detected through FTIR (a) scatter plot of samples in PC 1 vs. PC 2 (b) scatter plot of functional groups in PC 1 vs. PC 2 (Biplot) (c) scatter plot of PC 1. vs. PC 3 (d) scatter plot of functional groups in PC 1 vs. PC 3 (Biplot).

\subsection{Antibacterial Activity}

All extracts of $A$. bracteosa were screened for their antimicrobial activity against four bacterial strains, namely, Micrococcus luteus, Staphylococcus aureus, Enterobacter aerogenes, and Escherichia coli at a concentration of $100 \mu \mathrm{g} / \mathrm{mL}$. The results of antibacterial activity are shown in Table 2. Among all the strains tested, the plant extracts were more active against S. aureus and E. coli with ABRL3 yielding the highest zone of inhibitions (ZOIs) (16.2 \pm 0.7 and $16.2 \pm 0.5 \mathrm{~mm}$, respectively) at $100 \mu \mathrm{g} /$ disc. Overall, ABRL3 showed maximum antibacterial activity $(8.2 \pm 0.3-16.9 \pm 0.7 \mathrm{~mm} \mathrm{ZOI})$, and its ZOIs were comparable to the standard kanamycin $(23.7 \pm 1-26.2 \pm 1 \mathrm{~mm})$. DMSO, negative control, showed no inhibition against any bacterial strain. 
Table 2. Antibacterial activity of A. bracteosa.

\begin{tabular}{|c|c|c|c|c|c|c|c|c|}
\hline \multirow[b]{2}{*}{ Samples } & \multicolumn{8}{|c|}{ Zone of Inhibition at $100 \mu \mathrm{g} / \mathrm{Disc}(\mathrm{mm})$} \\
\hline & M. luteus & $\begin{array}{c}\text { MIC } \\
(\mu \mathrm{g} / \mathrm{mL})\end{array}$ & S. aureus & $\begin{array}{c}\text { MIC } \\
(\mu \mathrm{g} / \mathrm{mL})\end{array}$ & $\begin{array}{c}E . \\
\text { aerogenes }\end{array}$ & $\begin{array}{c}\text { MIC } \\
(\mu \mathrm{g} / \mathrm{mL})\end{array}$ & E. coli & $\begin{array}{c}\text { MIC } \\
(\mu \mathrm{g} / \mathrm{mL})\end{array}$ \\
\hline WT & $7.3 \pm 0.2^{\mathrm{e}}$ & - & $6.9 \pm 0.3^{f}$ & - & $6.5 \pm 0.1^{f}$ & - & $7.1 \pm 0.4^{\mathrm{f}}$ & - \\
\hline ABRL1 & $13.7 \pm 0.6^{\mathrm{c}}$ & $>100$ & $15.1 \pm 0.5^{b, c}$ & $>100$ & $8.3 \pm 0.2^{d}$ & - & $13.9 \pm 0.4^{\mathrm{c}}$ & $>100$ \\
\hline ABRL2 & $13.8 \pm 0.5^{c}$ & $>100$ & $15.5 \pm 0.4^{b}$ & $>100$ & $8.9 \pm 0.4^{\mathrm{d}}$ & - & $14.5 \pm 0.3^{c}$ & $>100$ \\
\hline ABRL3 & $16.1 \pm 0.6^{b}$ & $>100$ & $16.9 \pm 0.7^{b}$ & $>100$ & $8.2 \pm 0.3^{\mathrm{d}}$ & - & $16.2 \pm 0.5^{b}$ & $>100$ \\
\hline kanamycin & $26.2 \pm 1^{\mathrm{a}}$ & 0.31 & $25.1 \pm 2^{\mathrm{a}}$ & 0.33 & $23.7 \pm 1^{\mathrm{a}}$ & 0.29 & $24.4 \pm 3^{\mathrm{a}}$ & 0.30 \\
\hline
\end{tabular}

$\mathrm{WT}=$ in vitro grown untransformed Ajuga bracteosa plant extract; ABRL1-3 = crude extracts of transgenic lines 1, 2, and 3 of $A$. bracteosa; kanamycin $=$ positive drug; $\mathrm{MIC}=$ minimum inhibitory concentration. Data are represented as mean $\pm \mathrm{SD}(n=3)$. The values with different superscript $(\mathrm{a}-\mathrm{f})$ letters show significantly $(p<0.05)$ different means.

\subsection{The Antihemolytic Activity of Plant Extracts}

The antihemolytic activity of crude extracts of $A$. bracteosa was screened against normal human erythrocytes. WT and three transgenic lines exhibited a differential pattern of hemolytic effect towards human erythrocytes. The result indicated that the ABRL3 exhibited minimum hemolytic activity $\left(\mathrm{CC}_{50}=7293.05 \pm 7 \mu \mathrm{g} / \mathrm{mL}\right)$, whereas WT extracts showed the highest hemolytic activity $\left(\mathrm{CC}_{50}=1952.63 \pm 12 \mu \mathrm{g} / \mathrm{mL}\right)$. Lysis of erythrocytes was found to be increased with an increase of extract concentration (Table 3 ).

Table 3. Hemolytic activity of Ajuga bracteosa.

\begin{tabular}{|c|c|c|c|c|}
\hline \multirow{3}{*}{ Samples } & \multicolumn{3}{|c|}{$\%$ Hemolysis } & \multirow{3}{*}{$\mathrm{CC}_{50}(\mu \mathrm{g} / \mathrm{mL})$} \\
\hline & \multicolumn{3}{|c|}{ Test Concentrations $(\mu \mathrm{g} / \mathrm{mL})$} & \\
\hline & 1000 & 500 & 250 & \\
\hline WT & $16.25 \pm 2^{b}$ & $5.25 \pm 0.9^{c}$ & $2.97 \pm 1^{\mathrm{d}}$ & $1952.63 \pm 12$ \\
\hline ABRL1 & $9.76 \pm 1^{b, c}$ & $4.01 \pm 5^{\mathrm{c}, \mathrm{d}}$ & $0.82 \pm 0.07^{\mathrm{e}}$ & $5309.04 \pm 13$ \\
\hline ABRL2 & $8.43 \pm 0.8^{b, c}$ & $2.87 \pm 6^{\mathrm{d}}$ & $2.72 \pm 0.3^{\mathrm{d}}$ & $6179.54 \pm 9$ \\
\hline ABRL3 & $6.28 \pm 0.3^{c}$ & $2.41 \pm 4^{\mathrm{d}}$ & $0.88 \pm 0.1^{\mathrm{e}}$ & $7293.05 \pm 7$ \\
\hline AAPH & & $100^{\mathrm{a}}$ & & 0.07 \\
\hline
\end{tabular}

$\mathrm{WT}=$ in vitro grown untransformed Ajuga bracteosa plant extract; ABRL1-3 = crude extracts of transgenic lines 1 2 , and 3 of $A$. bracteosa; $\mathrm{AAPH}=$ positive control; $\mathrm{CC}_{50}=50 \%$ cytotoxic concentration. Data are represented as mean $\pm \mathrm{SD}(n=3)$. The values with different superscript $(\mathrm{a}-\mathrm{e})$ letters show significantly $(p<0.05)$ different means.

\subsection{Brine Shrimp Lethality Activity}

Brine shrimp assay was performed to monitor the cytotoxic potential of active compounds in different concentrations of extracts. Cytotoxicity results of all extracts of $A$. bracteos a are summarized in Table 4 . The lower the $\mathrm{LD}_{50}$ value, the more toxic the substance. In vitro grown WT plant showed the highest $\mathrm{LD}_{50}$ of $75.6 \pm 9 \mu \mathrm{g} / \mathrm{mL}$, whereas ABRL1 and ABRL2 showed the lowest $\mathrm{LD}_{50}$ values of $39.6 \pm 4 \mu \mathrm{g} / \mathrm{mL}$ and $41.62 \pm 2 \mu \mathrm{g} / \mathrm{mL}$, respectively, indicating a high level of toxicity in these extracts.

\subsection{Plant Extracts Inhibited Cancer Cell Growth in a Concentration-Dependent Manner}

To test the potent anticancer activity of the crude extracts of the A. bracteosa, HepG2, LM3, HT-29, A549, MCF-7, and MDA-MB-231 cancer cells were treated with different concentrations of plant extracts. In the present cytotoxicity analysis, all the plant extracts inhibited the cell growth with different efficacy depending on the specific plant extract and the cancer cell line tested. As can be seen in Figure 5a-f, the inhibition of cell growth was also in a concentration-dependent manner. Nevertheless, all the transgenic line extracts were most efficient against human liver carcinoma cells (HepG2, LM3), human lung adenocarcinoma cells (A549), and human colon carcinoma cells (HT-29) growth, even at lower concentrations. 
Table 4. Brine shrimp cytotoxicity of Ajuga bracteosa.

\begin{tabular}{|c|c|c|c|c|}
\hline \multirow{3}{*}{ Samples } & \multicolumn{3}{|c|}{$\%$ Mortality After $24 \mathrm{~h}$} & \multirow{3}{*}{$\mathrm{LD}_{50}(\mu \mathrm{g} / \mathrm{mL})$} \\
\hline & \multicolumn{3}{|c|}{ Test Concentrations $(\mu \mathrm{g} / \mathrm{mL})$} & \\
\hline & 200 & 66 & 21.8 & \\
\hline WT & $70.33 \pm 3^{b}$ & $50.4 \pm 2^{\mathrm{d}}$ & $30.3 \pm 3^{f}$ & $75.6 \pm 9$ \\
\hline ABRL1 & $79.3 \pm 5^{\mathrm{a}}$ & $60.3 \pm 2^{c}$ & $40.0 \pm 3^{e}$ & $39.6 \pm 4$ \\
\hline ABRL2 & $68.6 \pm 4^{b}$ & $58.6 \pm 1^{\mathrm{c}}$ & $40.6 \pm 2^{\mathrm{e}}$ & $41.62 \pm 2$ \\
\hline ABRL3 & $67.14 \pm 5^{b}$ & $59.2 \pm 3^{c}$ & $42.3 \pm 4^{\mathrm{e}}$ & $43.62 \pm 5$ \\
\hline Doxorubicin & & $84.65 \pm 10^{\mathrm{a}}$ & & $5.8 \pm 0.3$ \\
\hline
\end{tabular}

$\overline{\mathrm{WT}}=$ in vitro grown untransformed Ajuga bracteosa plant extract; ABRL1-3 = crude extracts of transgenic lines 1 , 2 , and 3 of $A$. bracteosa; Doxorubicin $=$ positive control; $\mathrm{LD}_{50}=$ median lethal dose. Data are represented as mean $\pm \mathrm{SD}(n=3)$. The values with different superscript $(\mathrm{a}-\mathrm{f})$ letters show significantly $(p<0.05)$ different means.
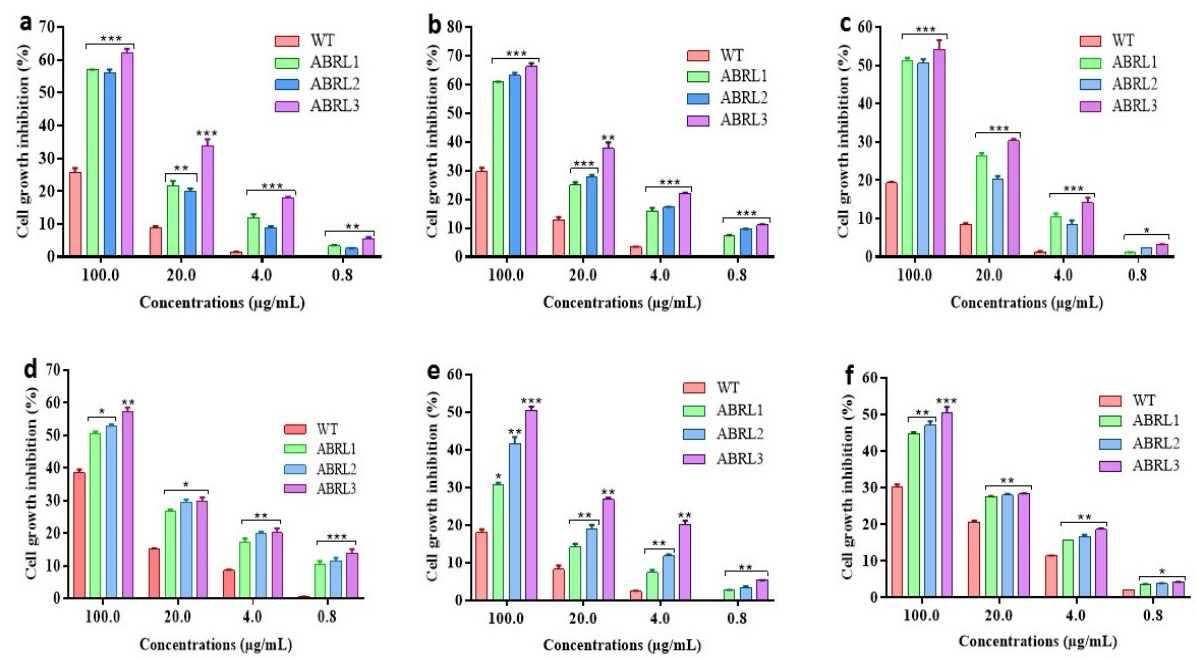

Figure 5. Cytotoxic activity of Ajuga bracteosa against (a) HepG2, (b) LM3, (c) HT-29, (d) A549, (e) MCF-7, and (f) MDA-MB-231. WT = wild type untransformed A. bracteosa plants; ABRL1-3 = transgenic lines 1-3 of A. bracteosa. Each value represents mean $\pm \operatorname{SD}(n=3) .{ }^{*} p<0.05$, ** $p<0.01$, and ${ }^{* * *} p<0.001$ are statistically significant data.

The $\mathrm{IC}_{50}$ values of WT and transgenic lines of $A$. bracteosa against selected cell lines are represented in Table 5. Among all the tested samples, ABRL3 showed the lowest $\mathrm{IC}_{50}$ of $57.1 \pm 2.2 \mu \mathrm{g} / \mathrm{mL}, 46.2 \pm 1.1 \mu \mathrm{g} / \mathrm{mL}, 72.4 \pm 1.3 \mu \mathrm{g} / \mathrm{mL}, 73.3 \pm 2.1 \mu \mathrm{g} / \mathrm{mL}$, $98.7 \pm 1.6 \mu \mathrm{g} / \mathrm{mL}$, and $97.1 \pm 2.5 \mu \mathrm{g} / \mathrm{mL}$ against HepG2, LM3, A549, HT29, MCF-7, and MDA-MB-231, respectively.

Table 5. $\mathrm{IC}_{50}$ values of cell proliferation inhibition of Ajuga bracteosa extracts.

\begin{tabular}{|c|c|c|c|c|c|c|}
\hline \multirow{2}{*}{ Treatment } & \multicolumn{6}{|c|}{$\mathrm{IC}_{50}(\mu \mathrm{g} / \mathrm{mL})$} \\
\hline & HepG2 & LM3 & A549 & HT-29 & MCF-7 & MDA-MB-231 \\
\hline WT & $>100$ & $>100$ & $>100$ & $>100$ & $>100$ & $>100$ \\
\hline ABRL1 & $71.2 \pm 3.1^{\mathrm{d}}$ & $58.3 \pm 2.3^{c}$ & $98.1 \pm 2.4^{\mathrm{f}}$ & $98.2 \pm 3.3^{f}$ & $>100$ & $>100$ \\
\hline ABRL2 & $79.5 \pm 4.6^{\mathrm{d}, \mathrm{e}}$ & $53.4 \pm 1.5^{c}$ & $94.2 \pm 1.7^{f}$ & $99.7 \pm 1.9^{f}$ & $>100$ & $>100$ \\
\hline ABRL3 & $57.1 \pm 2.2^{\mathrm{c}}$ & $46.2 \pm 1.1^{b}$ & $72.4 \pm 1.3^{\mathrm{d}}$ & $73.3 \pm 2.1^{\mathrm{d}}$ & $98.7 \pm 1.6^{f}$ & $97.1 \pm 2.5^{\mathrm{f}}$ \\
\hline Ellipticine & $0.38 \pm 0.01^{\mathrm{a}}$ & $0.47 \pm 0.04^{a}$ & $0.41 \pm 0.05^{a}$ & $0.39 \pm 0.04^{a}$ & $0.35 \pm 0.02^{a}$ & $0.45 \pm 0.03^{a}$ \\
\hline
\end{tabular}

WT $=$ in vitro grown untransformed Ajuga bracteosa plant extract; ABRL1-3 = crude extracts of transgenic lines 1, 2, and 3 of $A$. bracteosa; Ellipticine = standard anticancer drug; $\mathrm{IC}_{50}=$ half-maximal inhibitory concentration. Data are represented as mean $\pm \operatorname{SD}(n=3)$. The values with different superscript $(a-f)$ letters show significantly $(p<0.05)$ different means. 


\subsection{Antileishmanial Activity}

All the crude extracts were tested at three concentrations $(1000,500$, and $250 \mu \mathrm{g} / \mathrm{mL})$ for the cytotoxic activity against leishmanial promastigotes (Table 6). ABRL3 showed the most promising antileishmanial activity with an $\mathrm{IC}_{50}$ of $56.16 \pm 2 \mu \mathrm{g} / \mathrm{mL}$, followed by ABRL2 $\left(\mathrm{IC}_{50}=77.53 \pm 7 \mu \mathrm{g} / \mathrm{mL}\right)$, ABRL1 $\left(\mathrm{IC}_{50}=163.04 \pm 8 \mu \mathrm{g} / \mathrm{mL}\right)$, and WT $\left(\mathrm{IC}_{50}=313.99 \pm 6 \mu \mathrm{g} / \mathrm{mL}\right)$. Amphotericin B was used as a positive drug that displayed excellent cytotoxicity with an $\mathrm{IC}_{50}$ of $0.01 \mu \mathrm{g} / \mathrm{mL}$. DMSO (negative control) did not present any activity whatsoever.

Table 6. Antileishmanial activity of Ajuga bracteosa.

\begin{tabular}{|c|c|c|c|c|}
\hline \multirow{3}{*}{ Samples } & \multicolumn{3}{|c|}{$\%$ Mortality after $72 \mathrm{~h}$} & \multirow{3}{*}{$\mathrm{IC}_{50}(\mu \mathrm{g} / \mathrm{mL})$} \\
\hline & \multicolumn{3}{|c|}{ Test Concentrations $(\mu \mathrm{g} / \mathrm{mL})$} & \\
\hline & 1000 & 500 & 250 & \\
\hline $\mathrm{W}$ & $63.52 \pm 7^{d}$ & $55.64 \pm 4^{\mathrm{e}}$ & $47.23 \pm 2^{f}$ & $313.99 \pm 6$ \\
\hline ABRL1 & $78.14 \pm 1^{b}$ & $67.38 \pm 1^{\mathrm{c}}$ & $56.63 \pm 5^{\mathrm{e}}$ & $163.04 \pm 8$ \\
\hline ABRL2 & $75.48 \pm 6^{b}$ & $68.42 \pm 6^{c}$ & $61.69 \pm 6^{d}$ & $77.53 \pm 7$ \\
\hline ABRL3 & $74.53 \pm 8^{b}$ & $69.48 \pm 4^{c}$ & $62.14 \pm 3^{d}$ & $56.16 \pm 2$ \\
\hline Amphotericin B & & $100^{\mathrm{a}}$ & & 0.01 \\
\hline
\end{tabular}

$\mathrm{WT}=$ in vitro grown untransformed Ajuga bracteosa plant extract; ABRL1-3 = crude extracts of transgenic lines 1, 2 , and 3 of $A$. bracteosa; Amphotericin $\mathrm{B}=$ positive drug; $\mathrm{IC}_{50}=$ half-maximal inhibitory concentration. Data are represented as mean $\pm \mathrm{SD}(n=3)$. The values with different superscript $(\mathrm{a}-\mathrm{f})$ letters show significantly $(p<0.05)$ different means.

\section{Discussion}

Some bacterial species have a unique capability to mediate inter-kingdom DNA transfer by integrating and expressing their genes into the plant genome. Agrobacterium rhizogenes, one such example, has been readily utilized in plant genetic manipulation techniques to improve the production of pharmaceutically important secondary metabolites [24].

Agrobacterium-mediated transformation and generation of hairy roots have been reported for various species of the Ajuga genus [20,25-27]. Hairy roots are considered stable and easy-to-cultivate variants capable of producing special secondary metabolites by transformation with wild-type $A$. rhizogenes.

They contain a wide range of metabolites either comparable or sometimes even in higher amounts than the mother plant. However, certain metabolites show organ specificity for their synthesis and optimal activity, thus, requiring organogenesis from hairy roots [28].

In the current study, multiple transformation events generated 10 independent transgenic hairy root lines of Ajuga bracteosa. Based on their growth rate and metabolic content, only three such lines were selected to regenerate intact plants via somatic embryogenesis. These putatively transgenic plants exhibited distinct morphological alterations characteristic of rolABC transformed plants [20,29]. All the investigated transgenic lines displayed stunted growth and compact posture with reduced apical dominance. This supports the well-established paradigm of the strong association of rolB and rolC to stunted growth, and this has also been reported in tomato [30], potato, tobacco [31], and many species of Artemisia L. [29,32,33].

PCR analysis of the rolB gene in transgenic regenerants of $A$. bracteosa revealed a successful integration of T-DNA in the plant genome. While real-time qPCR confirmed the relatively higher expression of the rolB gene in all transgenic lines. The rol $A B C$ oncogenes not only regulate hormone-controlled morphogenesis but also powerfully induce plant secondary metabolism [34]. Previously, we found enhanced expression of metabolic pathway genes under the influence of rolABC in A. bracteosa regenerated plants [35]. This enhanced expression can be linked with significantly higher amounts of several polyphenols, as shown in our previous study [36]. Here, among all the tested plants, ABRL3 displayed the highest phenolic content, flavonoid content, antioxidant capacity, radical scavenging, and metal chelating power. Previously, rolB genes improved the antioxidants 
lycopene and ascorbic acid in transgenic tomato plants [30]. Moreover, rolB and rolC transgenic-Artemisia carvifolia plants showed an increased amount of Artemisinin, a natural sesquiterpene lactone utilized against malaria and as an anti-cancer agent [32]. Likewise, $\mathrm{rolC}$ is reported to increase antioxidant, anti-inflammatory, antidepressant, and analgesic properties in lettuce [37]. Further, rolA and rolC-transgenic tissues exhibit increased production of anthraquinones [38,39], ginsenosides [40], resveratrol [41], and nicotine [42]. These effects are probably due to the influence of rol genes on the increased transcription of isochorismate synthase gene, calcium-dependent protein kinase gene expression, activation of genes encoding MYB and bHLH transcription factors, and many other genes involved in biosynthetic pathways [21].

In the current study, FTIR analysis revealed the presence of amines, alkanes, alcohols, aromatic compounds, ketones, phenolics, amino acids, and carboxylic acids in crude extracts. The absorption peaks between $1700-3300 \mathrm{~cm}^{-1}$, corresponding to the $\mathrm{O}-\mathrm{H}$ group, indicate the presence of medicinally important alcohols, acids, phenols, and their derivatives [43]. The IR spectra at $1147 \mathrm{~cm}^{-1}$ and $1148 \mathrm{~cm}^{-1}$, representing ether $\mathrm{R}=\mathrm{C}-\mathrm{O}-\mathrm{C}$, were only found in ABRL2 and ABRL3. Moreover, $\mathrm{C}=\mathrm{O}$ stretching at $1708 \mathrm{~cm}^{-1}$ in ABRL2 and ABRL2 is due to the derivatives of gallic acid and other tannins. The absorption at $1200-1400 \mathrm{~cm}^{-1}$ shows the presence of a flavonoids-C ring [44]. FTIR spectra coupled with PCA revealed the similarities and differences between multiple lines of $A$. bracteosa based on the presence of functional groups and absorption spectra.

Antimicrobial resistance poses a serious threat to the effective treatment of an everincreasing range of infections. This increasing resistance has created a need to develop new antimicrobial agents. In the last years, a rational approach to deal with antibiotic resistance problems using a combination therapy combining conventional antibiotics, plant extracts, and essential oils has been proposed [45-47]. In this study, we explored the potential antibacterial activity of $A$. bracteosa crude extracts. For this, we used four bacterial strains $M$. luteus, S. aureus, E. aerogenes, and E. coli. Our investigation exhibited moderate antibacterial activity of WT as well as transgenic line extracts. Each extract acted differently and showed variation in the antibacterial activity against each bacterial strain. Overall, the following tendency of microbial sensitivity to plant extracts was observed: S. aureus $>$ E. coli $>$ M. luteus $>$ E. aerogenes. Previously, 14, 15-dihydroajugapitin and 8-oacetylharpagide isolated from the methanolic extracts of aerial parts of $A$. bracteosa showed significant antibacterial activity [48]. The synergistic effect of phytochemicals of $A$. bracteosa against different bacterial pathogens is also evident from published literature [49-51]. Various data show that antibacterial mechanisms of polyphenols primarily involve inhibition of synthesis of bacterial DNA and RNA, inhibition of cytoplasmic membrane function, and interaction with some crucial bacterial enzymes [2].

The antihemolytic assay aimed to assess whether A. bracteosa prevented 2,2'-azobis (2amidinopropane) dihydrochloride (AAPH)-induced oxidative damages to the erythrocyte membrane or not. Here, we observed that the incubation of RBCs with the A. bracteosa crude extracts did not induce hemolysis, indicating that these extracts are non-toxic and harmless for the cells. We also found that all transformed plant extracts significantly protected the erythrocyte membrane from hemolysis in a concentration-dependent manner. It is speculated that antioxidants, particularly polyphenols, present in the extract are mobilized to fight off the oxidant attack by binding to the RBC membrane matrix near tryptophan residues. They protect the integrity of RBCs, resulting in the delay of hemolysis $[52,53]$. Moreover, Rehman et al. (2015) [50] successfully demonstrated the dose-dependent antilipid peroxidation activity of $A$. bracteosa extracts, which also accounts for the antihemolytic potential of this plant. However, the antihemolytic activity of $A$. bracteosa has never been reported earlier.

Brine shrimp assay was performed to check the cytotoxic potential of plant extracts. Based on the results, all the extracts of $A$. bracteosa showed significant cytotoxicity $\left(\mathrm{LD}_{50}<100 \mu \mathrm{g} / \mathrm{mL}\right)$ against brine shrimp nauplii eggs. Among all the tested extracts, ABRL1 showed the lowest $\mathrm{LD}_{50}$ value $(39.6 \pm 5 \mu \mathrm{g} / \mathrm{mL})$, followed by ABRL2 $(41.62 \pm 2 \mu \mathrm{g} / \mathrm{mL})$, 
ABRL3 (43.62 $\pm 5 \mu \mathrm{g} / \mathrm{mL})$, and WT $(75.6 \pm 9 \mu \mathrm{g} / \mathrm{mL})$. Previously, several other researchers also reported promising brine shrimp cytotoxic activity of crude extracts of $A$. bracteosa in different solvent systems. Rehman et al. [50] reported that the $n$-hexane fractions of $A$. bracteosa displayed an $\mathrm{LD}_{50}$ of $370.6 \mu \mathrm{g} / \mathrm{mL}$, whereas Imran et al. (2021) [54] described significantly higher cytotoxic activity in ethyl acetate extracts of A. bracteosa. Moreover, Zehra et al. (2017) [49] noted the most potent brine shrimp cytotoxicity in ethanolic, acetone-distilled water, methanol-distilled water extracts of $A$. bracteos $a$ with the LD $_{50}$ of $46.72 \pm 0.18,51.63 \pm 1.18$, and $63.52 \pm 1.70 \mu \mathrm{g} / \mathrm{mL}$, respectively. These results confirm the presence of cytotoxic substances in the crude extracts of $A$. bracteosa.

At present, the undesirable clinical consequences of synthetic anti-cancer drugs and other chemopreventive measures have forced researchers to turn to natural products. In recent years, several studies have demonstrated the anti-cancer potential of plant extracts. Their beneficial effects are due to a complex interplay of the composite mixture of compounds present in the whole plant rather than constituent single agents alone [55]. Keeping this, we investigated the anticancer properties of $A$. bracteosa against various cancer cell lines. Cell growth inhibition of all six cancer lines, including HepG2, LM3, HT-29, A549, MCF-7, and MDA-MB-231, was measured after treatment with crude extracts of wild-type plants and transgenic regenerants. All plant extracts were found to be more effective against HepG2, LM3, HT-29, and A549 than MCF-7 and MDA-MB. Previously, the methanolic extracts of areal parts of $A$. bracteosa demonstrated significant cytotoxicity against MCF-7 with an $\mathrm{IC}_{50}$ of $10 \mu \mathrm{g} / \mathrm{mL}$ [56]. In another study, the polar extracts of $A$. bracteosa exhibited significant activity against the human leukemia cell line (TPH-1), whereas nonpolar and moderately polar extracts were more effective against the MCF-7 cell line [49]. This is in accordance with our results as all our extracts (except ABRL3) were least effective against MCF-7 and MD-MB-231, showing an $\mathrm{IC}_{50}$ of more than $100 \mu \mathrm{g} / \mathrm{mL}$ due to their higher polarity. Thus, we found a dose-dependent anticancer effect of $A$. bracteosa against human liver cancer, colon cancer, lung cancer, and human breast cancer cell lines. The traditional use of $A$. bracteosa against sore throat, cough, diarrhea, dysentery, and digestive disorders [57] supports these findings. Furthermore, Yousaf et al. (2018) [19] reported the antiviral activity of methanolic extracts of $A$. bracteosa in a time-dependent manner. These extracts decreased the hepatitis- $C$ viral count by $75 \%$ following $48 \mathrm{~h}$ treatment of HCV-infected HepG2 cells.

Herbal plants are the best alternatives in the development of new antileishmanial agents due to their selective action against parasites without reducing the host cell viability [15]. This research aimed to explore the therapeutic effects of $A$. bracteosa extract as an anti-parasitic herbal drug. We found the significant cytotoxic activity of $A$. bracteosa extracts formulations against leishmanial promastigotes. The achieved results demonstrated that ABRL3 was the most promising antileishmanial agent followed by ABRL2, ABRL1, and WT extracts. Our findings are in agreement with some of the previous studies reporting the antileishmanial activity of $A$. bracteosa crude extracts. Dose-dependent cytotoxicity was observed with a significant mortality rate of $63.18 \pm 2.29$ and $58.44 \pm 1.61$ for n-hexane, $57.20 \pm 1.19$ and $48.39 \pm 1.09$ for ethanolic extracts of $A$. bracteosa at $1000 \mu \mathrm{g} / \mathrm{mL}$ for promastigote and amastigotes form of the leishmanial parasite, respectively [54]. Similarly, n-hexane, n-hexane-ethyl acetate, chloroform, and $n$-hexane-ethanol extracts of $A$. bracteosa showed excellent leishmanicidal activity with the $\mathrm{IC}_{50}$ of $4.69 \pm 0.01,12.16 \pm 0.02$, $28.62 \pm 0.03$, and $40.1 \pm 0.02 \mu \mathrm{g} / \mathrm{mL}$, respectively [49]. This information can be used to isolate and characterize the pure compounds from $A$. bracteosa as a source of antileishmanial drugs.

\section{Material and methods}

\subsection{Plant Source}

Fresh, green, viable plants were collected from Islamabad, Pakistan. The sample was formally identified, and a voucher specimen (numbered HPM-460) was placed in the departmental herbarium. The collected plants were surface sterilized, and tissue cultured 
on Murashige and Skoog (MS) medium. Transgenic hairy roots were generated through rolABC genes of Agrobacterium rhizogenes (LBA-9402) mediated transformation. Intact plants were regenerated from transgenic hairy roots by following the previously optimized method in our lab [20].

\subsection{Confirmation of Genetic Integration by $P C R$ and RT-PCR}

Genomic DNA was isolated from three independent transgenic lines and wild plants of A. bracteosa. For genomic DNA isolation, the cetyl trimethyl ammonium bromide (CTAB) method [58] was employed. The Alkali lysis method [59] was used to isolate the plasmid DNA of $A$. rhizogenes. Conventional PCR was used to confirm the presence of the rolB gene in putatively transformed and regenerated plants. The recipe for PCR reaction mixture preparation and amplification conditions for the detection of the rolB gene were already optimized and used accordingly [60]. The primer sequences used for the rolB gene are presented in Table 7 .

Table 7. The gene primer sequences.

\begin{tabular}{cccc}
\hline Genes & $\begin{array}{c}\text { GenBank } \\
\text { Accession No. }\end{array}$ & Primer Sequences \\
\hline House Keeping Genes & & F: GATTGAGCACGGTATTGTTAG \\
$\beta$ Actin & DQ531565 & R: ACACCATCACCAGAATCCAAC & 259 \\
$18 \mathrm{~s}$ & H: GGAGAGGGAGCCTGAGAAAC & R: GATTTAGATTGTACTCATTCC \\
Agrobacterium rhizogenes genes & & F: CGAGGGACTGAAAACCGCC \\
rolB (qPCR) & X03433 & R: CCGAGAGTCGCAGGGTTAG & 127 \\
rolB (Simple PCR) & X15952.1 & R: GATCTTGCAGTGCTAGATTT & 779 \\
\hline
\end{tabular}

The TRIzol ${ }^{\circledR}$ /ice-based method [61] was employed to isolate RNA from wild-type plants and transgenic lines for expression analysis of the rolB gene. Then, the Viva cDNA synthesis kit (Vivantis cDSK01-050) was used to synthesize cDNA from $1 \mu \mathrm{g}$ of isolated RNA by reverse transcription. This whole procedure was performed by following the manufacturer's instructions, and synthesized cDNA was stored at $-20^{\circ} \mathrm{C}$ for further analysis.

Before performing the real-time experiment, the qPCR conditions were optimized for genes encoding rolB, $\beta$-actin, and 18 s, accordingly. The gene-specific primers used for the amplification reaction are given in Table 1. The qPCR was conducted using a Mic PCR machine (BioMolecular Systems, Upper Coomera, QLD, Australia) with a 1X Eva Green PCR master mix (Phenix Research Products, Candler, NC, USA). For real-time qPCR, a 1:10 dilution of cDNA was used. The reaction conditions for qPCR were as follows: an initial cycle of denaturation for $12 \mathrm{~min}$ at $95^{\circ} \mathrm{C}$, followed by 40 cycles each of denaturation for $15 \mathrm{~s}$ at $95^{\circ} \mathrm{C}$, primer annealing for $20 \mathrm{~s}$ at $60^{\circ} \mathrm{C}$ (for all genes), and elongation for $20 \mathrm{~s}$ at $72{ }^{\circ} \mathrm{C}$. Three biological samples were analyzed, while three technical replicates were used for each biological sample. The melting curve of amplicons confirmed the absence of primer dimers at the end of each run. The relative gene expression levels were normalized with the endogenous reference genes ( $\beta$-actin and 18s) [62].

\subsection{Crude Extract Preparation}

Whole plants of WT and three independent transgenic lines (ABRL1, 2, and 3) of $A$. bracteosa were taken. Any growth media attached to the plants was removed by rinsing with water. Washed plants were shade dried for a week. Dried plants were ground into powder form, and $1 \mathrm{~g}$ powdered material was blended with a mixture of methanol: chloroform (1:1; $5 \mathrm{~mL}$ ). This was allowed to set for $1 \mathrm{~h}$, then the mixture was sonicated for $10 \mathrm{~min}$, followed by $20 \mathrm{~min}$ of shaking, and the process was repeated three times. Finally, the plant extracts 
were filtered, and pooled filtrates were dried, weighed, and stored at room temperature for downstream analysis.

\subsection{Identification of Functional Groups by Fourier Transform Infra-Red (FTIR) Spectroscopy}

FTIR spectroscopy analysis of $A$. bracteosa crude extracts was performed to determine structural modifications (functional groups) between wild-type and transgenic plants through the identification of chemical bonds of phytoactive compounds. FTIR analysis was conducted using Perkin-Elmer Tensor 27 FTIR spectrophotometer (Bruker, Waltham, MA, USA) in the range of $4000-400 \mathrm{~cm}^{-1}$ with a resolution of $1 \mathrm{~cm}^{-1}$ and intensity mode as \% Transmittance. Spectra were taken in triplicate for each sample without previous treatment [44]. Principal component analysis (PCA) was performed by using PAST 4.03 statistical software.

\subsection{Antibacterial Activity}

The antibacterial activity of the crude extracts of $A$. bracteosa was evaluated by the disc diffusion method [49]. In this experiment, two Gram-positive bacterial strains, Micrococcus luteus (ATCC 10,240) and Staphylococcus aureus (ATCC 6538), and two Gram-negative strains, Enterobacter aerogenes (ATCC 13,048) and Escherichia coli (ATCC 15,224), were precultured in nutrient broth for $24 \mathrm{~h}$ at $37^{\circ} \mathrm{C}$. Then, each refreshed bacterial strain was inoculated to the nutrient agar medium at $45{ }^{\circ} \mathrm{C}$, poured into sterile petri plates, and allowed to solidify. After that, $5 \mu \mathrm{L}$ of the crude extracts with a final concentration of $100 \mu \mathrm{g} / \mathrm{mL}$ was poured on sterile filter paper discs $(4 \mathrm{~mm})$ and placed on nutrient agar plates. On each plate, kanamycin $(4 \mathrm{mg} / \mathrm{mL}$. Sigma-Aldrich, St. Louis, MO, USA) was used as positive control and DMSO (Dimethylsulfoxide, Sigma-Aldrich, St. Louis, MO, USA) as a negative control. The assay was performed in triplicate and the plates were incubated at $37{ }^{\circ} \mathrm{C}$ for a period of $24 \mathrm{~h}$. The antibacterial activity of the extracts was determined by measuring the diameter of zones showing complete inhibition ( $\mathrm{mm}$ ) with the help of the Vernier caliper. An inhibition zone $\geq 10 \mathrm{~mm}$ in diameter was considered active for the tested samples and further screening was done by three-fold micro broth dilution method to determine the minimum inhibitory concentration (MIC). Briefly, the stock solution ( $40 \mathrm{mg} / \mathrm{mL}$ ) of each active sample (inhibition zone $\geq 10 \mathrm{~mm}$ ) was used to prepare the master plate of concentration $8 \mathrm{mg} / \mathrm{mL}$ in sterile Mueller Hinton broth (MHB). Then these samples were serially diluted in a 96-well microtiter plate with sterile $\mathrm{MHB}$ to obtain the final concentration ranging from 7.41 to $200 \mu \mathrm{g} / \mathrm{mL}$. Subsequently, a standardized inoculum $\left(5 \times 10^{4} \mathrm{CFU} / \mathrm{mL}\right)$ for each bacterial strain was poured into each well. These plates were then kept at $37{ }^{\circ} \mathrm{C}$ for overnight incubation. The lowest concentration at which the extract exhibited visible growth inhibition was designated as its MIC.

\subsection{Anti-Hemolytic Assay}

To evaluate the possible hemolytic effect of crude extract of transformed and wildgrown $A$. bracteosa, an anti-hemolysis assay was performed. For this, hemolysis was induced by AAPH radicals [63]. Briefly, $5 \mathrm{~mL}$ blood was obtained from a unanimous human donor by venipuncture in an Ethylenediaminetetraacetic acid (EDTA) tube. The collected blood was diluted with phosphate buffer saline (PBS; $1: 3$ ). The erythrocytes from the blood were collected through centrifugation at $1500 \times g$ for $10 \mathrm{~min}$. The pellet was washed twice with PBS (Sigma-Aldrich, St. Louis, MO, USA) while the supernatant was discarded. Washed erythrocytes were further diluted with PBS and treated with plant extracts at three different concentrations $(1000,500$, and $250 \mu \mathrm{g} / \mathrm{mL})$. AAPH treated blood was used as a positive reference while PBS was taken as the negative control. The mixtures were allowed for an incubation period of $1 \mathrm{~h}$ at $37^{\circ} \mathrm{C}$. Final centrifugation was given to the samples at the above-mentioned conditions. For hemolysis measurement, $200 \mu \mathrm{L}$ of the 
supernatant from each treated sample was taken and absorbance was recorded at $570 \mathrm{~nm}$. The percent hemolysis for each extract was calculated using the following formula.

$$
\text { Percent hemolysis }=\frac{\text { A570nm of Sample }- \text { A570nm of Negative control }}{\text { A570nm of Positive control }- \text { A570nm of Negative control }} \times 100
$$

$\mathrm{CC}_{50}(50 \%$ cytotoxic concentration) values were calculated from percent hemolysis.

The study protocol complied with the Helsinki Declaration. Study approval (BEC-FBSQAU2019-157) was obtained from the Ethical Review Committee, Quaid-i-Azam University. Islamabad. Informed consent was obtained from persons who participated in the study.

\subsection{Brine Shrimp Cytotoxicity Assay}

A brine shrimp assay was performed to check the cytotoxicity of plant extracts [64]. A stock solution $(40 \mathrm{mg} / \mathrm{mL})$ of each test sample was prepared. From this stock solution, further dilutions $(200,66$, and $21.8 \mu \mathrm{g} / \mathrm{mL})$ were made. Then, $25 \mu \mathrm{L}$ from each dilution was taken in a transparent glass vial and mixed in $2 \mathrm{~mL}$ of seawater. Ten live shrimps of Artemia salina were aspirated by gentle pipetting and transferred to each vial, raising the volume to $5 \mathrm{~mL}$ by adding seawater. This reaction mixture was kept under illumination at room temperature for $24 \mathrm{~h}$. Then, the number of shrimps alive was counted with the help of a $3 \times$ magnifying glass. The experiment was performed in triplicate. Doxorubicin (4 mg/mL, Sigma-Aldrich, St. Louis, MO, USA) was used as positive control, while DMSO was the negative control.

$$
\text { Percent mortality }=\frac{\text { No. of shrimps alive in test }- \text { No. of shrimps alive in control }}{\text { No. of shrimps alive in control }} \times 100
$$

The median lethal dose $\left(\mathrm{LD}_{50}\right)$ of the test samples with $\geq 50 \%$ mortality was calculated using table curve 2D v5.01 software.

\subsection{Antiproliferative Activity}

\subsubsection{3-(4,5-Dimethylthiazol-2-yl)-2,5-Diphenyl-2H-Tetrazolium Bromide (MTT) Assay}

An MTT assay was performed to assess the antiproliferative activity of plant extracts under study. MTT assay is a colorimetric technique based on the ability of the living cells to transform tetrazolium salt 3-(4,5-dimethylthiazol-2-yl)-2,5-diphenyltetrazolium bromide (MTT) by the mitochondria into a formazan, a characteristic purple precipitate [65]. For that purpose, six cancer cell lines were used, including HepG2 and LM3 (derived from hepatic carcinoma), HT-29 (derived from colon cancer cells), A549 (derived from lung adenocarcinoma), and MCF-7 and MDA-MB-231 (derived from breast carcinoma). All these cell lines were purchased from ATCC (Manassas, VA, USA).

\subsubsection{Sample Preparation for MTT Assay}

Dried crude extracts of different plant samples were dissolved in 5\% $(v / v)$ DMSO (20 mg/mL). Ellipticine (Sigma-Aldrich, St. Louis, MO, USA) was used as reference positive control, while the cells treated only with the solvent ( $5 \%$ DMSO) were used as a negative control.

\subsubsection{Maintenance of Cell Cultures}

All the cell lines were cultured in RPMI 1640 medium supplemented with 10\% heatinactivated fetal bovine serum (Bio West, Miami, FL, USA) and 1\% antibiotic-penicillin/ streptomycin (Invitrogen, Carlsbad, CA, USA). Cells grown as monolayer cultures in T75 flasks Costar were subcultured twice a week at $37{ }^{\circ} \mathrm{C}$ and $5 \% \mathrm{CO}_{2}$ in a humidified atmosphere and maintained at low passage number ( 5 to 20 ).

For the cytotoxicity assay, 4-6 $\times 10^{4}$ cells/well for different cell lines were seeded in a 12-well plate. Cells were grown for $24 \mathrm{~h}$, and then plant extracts were added at different concentrations $(100,20,4$, and $0.8 \mu \mathrm{g} / \mathrm{mL})$ to the medium in the respective well, analyzing the toxicity after $72 \mathrm{~h}$. All the conditions were run in triplicate. 


\subsubsection{Assay Procedure}

The growth medium was removed and $0.63 \mathrm{mM}$ of MTT and $18.4 \mathrm{mM}$ of sodium succinate (Sigma-Aldrich, St. Louis, MO, USA) were added to $1 \mathrm{~mL}$ of fresh culture medium, and the cells were incubated for $3 \mathrm{~h}$ at $37^{\circ} \mathrm{C}$. Then, the medium was removed, and the formazan was resuspended in DMSO supplemented with $0.57 \%$ acetic acid and $10 \%$ SDS (Sigma-Aldrich, St. Louis, MO, USA). Absorbance was measured at $570 \mathrm{~nm}$ by an ELISA reader (Elx 800, BioTek, San Diego, CA, USA) [32].

\subsection{Anti-Promastigote Assay}

The selected plant extracts were screened for antileishmanial activity by the MTT assay [66]. Promastigotes of Leishmania tropica were cultured in Medium-199 supplemented with $10 \%$ fetal bovine serum (FBS, Sigma-Aldrich, St. Louis, MO, USA), $100 \mathrm{IU} / \mathrm{mL}$ penicillin $\mathrm{G}$, and $100 \mu \mathrm{g} / \mathrm{mL}$ streptomycin sulfate (Sigma-Aldrich, St. Louis, MO, USA) and incubated at $24^{\circ} \mathrm{C}$ for $6-7$ days until the culture count reached from $4-5$ million $/ \mathrm{mL}$. The culture was counted using the Neubauer chamber during the log phase. Plant extracts were taken in a 96-well plate in three different concentrations: 1000, 500, and $250 \mu \mathrm{g} / \mathrm{mL}$ in triplicate. Amphotericin B (Sigma-Aldrich, St. Louis, MO, USA) was used as a reference drug, while DMSO $(0.5 \%)$, being non-toxic to leishmanial parasite growth, was used as a negative control. A $100 \mu \mathrm{L}$ of the complete culture $\left(10^{6}\right.$ cells $\left./ \mathrm{mL}\right)$ was seeded to the $96-$ well plate already containing the screening samples at three different concentrations. The plate was incubated for $72 \mathrm{~h}$ at $25^{\circ} \mathrm{C}$. The viability of the promastigotes of all compounds was assessed by the MTT colorimetric method; $100 \mu \mathrm{L}$ of the MTT dye was added to each well and re-incubated for $3 \mathrm{~h}$ at $37^{\circ} \mathrm{C}$. Finally, $40 \mu \mathrm{L}$ of the DMSO was added as a stop solution. The absorbance was recorded using an ELISA plate reader (Elx 800, BioTek, San Diego, CA, USA) at $570 \mathrm{~nm}$. The percent cytotoxicity of the extracts was calculated using the given formula:

$$
\text { Percent cytoxicity }=\frac{\text { A570 } \mathrm{nm} \text { of the Treated sample }}{\mathrm{A} 570 \mathrm{~nm} \text { of Control sample }} \times 100
$$

$\mathrm{IC}_{50}$ (half-maximal inhibitory concentration) values of the test samples with $\geq 50 \%$ cytotoxicity were calculated by using percent hemolysis.

\subsection{Statistical Analysis}

All the analyses were performed in triplicate, and values were represented as mean $(n=3) \pm \mathrm{SD}$. For qPCR analysis, three biological and three technical replicates were used for each sample. One-way analysis of variance (ANOVA) was used to find the significance of the difference between wild-type control plants and transgenic lines through GraphPad Prism Software Version 7.0 (GraphPad Prism ${ }^{\circledR}$ Software, Inc. San Diego, CA, USA). $p \leq 0.05$ was considered statistically significant. PAST 4.03 statistical software was used for principal component analysis (PCA) of FTIR spectra. $\mathrm{LD}_{50}$ of the test samples was calculated using table curve 2D v5.01 software.

\section{Conclusions}

In conclusion, present findings suggest that transgenic $A$. bracteosa plants are a rich source of metabolites that correlate with $\mathrm{rolB}$ gene expression. Generally, all transgenic lines showed significant antihemolytic, brine shrimp cytotoxic, anticancer, and antileishmanial activity. Overall, these results suggest that $A$. bracteosa extracts can be employed as futuristic possibilities for medicinal plants as a replacement to current anti-leishmanial and anticancer therapies. However, further studies are needed to uncover the potential molecular mechanism of $A$. bracteosa against these aggressive diseases.

Author Contributions: Conceptualization, S.R. and B.M.; data curation, S.R.; formal analysis, S.R. and N.A.; funding acquisition, M.K.O.; investigation, S.R. and H.-Q.D.; methodology, S.R.; project administration, B.M.; software, I.U.K.; supervision, B.M.; validation, M.A.E.-T. and Z.K.A.; visualiza- 
tion, M.Z.B. and Y.B.E.; writing-original draft, S.R. and I.M.M.; writing-review and editing, M.K.O., K.S.A. and B.M. All authors have read and agreed to the published version of the manuscript.

Funding: This research was funded by a grant from the Research Group Program (RG-1441-485), Deanship of Scientific Research, King Saud University, Riyadh, Saudi Arabia.

Institutional Review Board Statement: The study was conducted according to the guidelines 425 of the Organization for Economic Corporation and Development (OECD) and approved by the Ethical Committee, Quaid i Azam University, Islamabad, Pakistan (BEC-FBS-QAU2019-157).

Informed Consent Statement: Informed consent was obtained from all subjects involved in the study.

Data Availability Statement: The datasets used and/or analyzed during the current study are available from the corresponding author on reasonable request.

Acknowledgments: The authors extend their appreciation to King Saud University for funding this work through research grant No (RG-1441-485). We are thankful to technical staff from Laboratory Center, Hanoi University of Public Health, Vietnam, for providing the technical support. We also acknowledge Waqas Khan Kayani, Department of Biotechnology, Faculty of Sciences, University of Kotli, Azad Jammu and Kashmir, Pakistan, for providing the plant material.

Conflicts of Interest: The authors declare no conflict of interest.

Sample Availability: Samples of plant material are available from the authors.

\section{References}

1. Bisi-Johnson, M.A.; Obi, C.L.; Samuel, B.B.; Eloff, J.N.; Okoh, A.I. Antibacterial activity of crude extracts of some South African medicinal plants against multidrug resistant etiological agents of diarrhoea. BMC Complement. Altern. Med. 2017, 17, 321. [CrossRef] [PubMed]

2. Adamczak, A.; Ożarowski, M.; Karpiński, T.M. Antibacterial activity of some flavonoids and organic acids widely distributed in plants. J. Clin. Med. 2020, 9, 109. [CrossRef]

3. Granato, D.; Mocan, A.; Câmara, J.S. Is a higher ingestion of phenolic compounds the best dietary strategy? A scientific opinion on the deleterious effects of polyphenols in vivo. Trends Food Sci. Technol. 2020, 98, 162-166. [CrossRef]

4. García-Becerra, L.; Mitjans, M.; Rivas-Morales, C.; Verde-Star, J.; Oranday-Cárdenas, A.; María, P.V. Antioxidant comparative effects of two grape pomace Mexican extracts from vineyards on erythrocytes. Food Chem. 2016, 194, 1081-1088. [CrossRef]

5. Balderrama-Carmona, A.P.; Silva-Beltrán, N.P.; Gálvez-Ruiz, J.C.; Ruíz-Cruz, S.; Chaidez-Quiroz, C.; Morán-Palacio, E.F. Antiviral, antioxidant, and antihemolytic effect of Annona muricata L. leaves extracts. Plants 2020, 9, 1650. [CrossRef] [PubMed]

6. da Silva, A.C.; do Nascimento, R.M.; do Nascimento Rodrigues, D.C.; Ferreira, P.M.; Pessoa, C.; Lima, D.J.; de Moraes Filho, M.O.; de Almeida, R.M.; Ferreira, S.R.; Fujiwara, R.T.; et al. In vitro activity evaluation of seven Brazilian Asteraceae against cancer cells and Leishmania amazonensis. S. Afr. J. Bot. 2019, 1, 267-273. [CrossRef]

7. World Health Organization. Cancer-WHO. Available online: http:/ /www.who.int/cancer/en (accessed on 14 August 2021).

8. The Cancer Atlas. Southern, Eastern, and South-Eastern Asia. Available online: https://canceratlas.cancer.org/the-burden/ south-east-se-asia (accessed on 10 August 2021).

9. Deng, L.J.; Qi, M.; Li, N.; Lei, Y.H.; Zhang, D.M.; Chen, J.X. Natural products, and their derivatives: Promising modulators of tumor immunotherapy. J. Leukoc. Biol. 2020, 108, 493-508. [CrossRef] [PubMed]

10. Gelani, C.D.; Uy, M.M. Cytotoxicity to Artemia salina L. of marine sponge extracts from Surigao del Norte, Phillipines. Bull. Env. Pharmacol. Life Sci. 2016, 55, 14-18.

11. Niksic, H.; Becic, F.; Koric, E.; Gusic, I.; Omeragic, E.; Muratovic, S.; Miladinovic, B.; Duric, K. Cytotoxicity screening of Thymus vulgaris L. essential oil in brine shrimp nauplii and cancer cell lines. Sci. Rep. 2021, 11, 13178. [CrossRef]

12. Schwing, A.; Pomares, C.; Majoor, A.; Boyer, L.; Marty, P.; Michel, G. Leishmania infection: Misdiagnosis as cancer and tumor-promoting potential. Acta Trop. 2019, 1, 104855. [CrossRef]

13. Khan, N.H.; ul Bari, A.; Hashim, R.; Khan, I.; Muneer, A.; Shah, A.; Wahid, S.; Yardley, V.; O’Neil, B.; Sutherland, C.J. Cutaneous leishmaniasis in Khyber Pakhtunkhwa province of Pakistan: Clinical diversity and species-level diagnosis. Am. J. Trop. Med. Hyg. 2016, 2, 1106. [CrossRef] [PubMed]

14. Al-Kamel, M.A. Leishmaniasis and malignancy: A review and perspective. Clinic. Skin Cancer 2017, 1, 54-58. [CrossRef]

15. Badirzadeh, A.; Heidari-Kharaji, M.; Fallah-Omrani, V.; Dabiri, H.; Araghi, A.; Salimi Chirani, A. Antileishmanial activity of Urtica dioica extract against zoonotic cutaneous leishmaniasis. PLoS Negl. Trop. Dis. 2020, 14, e0007843. [CrossRef] [PubMed]

16. Singh, R.; Patil, S.M.; Pal, G.; Ahmad, M. Evaluation of in vivo and in vitro anti-inflammatory activity of Ajuga bracteosa Wall ex Benth. Asian Pac. J. Trop. Dis. 2012, 2, 404-407. [CrossRef]

17. Hsieh, W.T.; Liu, Y.T.; Lin, W.C. Anti-inflammatory properties of Ajuga bracteosa in vivo and in vitro study and their effects on mouse model of liver fibrosis. J. Ethnopharmacol. 2011, 135, 116-125. [CrossRef] 
18. Ganaie, H.A.; Ali, M.N.; Ganai, B.A.; Kaur, J.; Ahmad, M. GC-MS analysis and evaluation of mutagenic and antimutagenic activity of ethyl acetate extract of Ajuga bracteosa wall ex. benth: An endemic medicinal plant of Kashmir Himalaya, India. J. Clinic. Toxicol. 2016, 6, 288. [CrossRef]

19. Yousaf, T.; Rafique, S.; Wahid, F.; Rehman, S.; Nazir, A.; Rafique, J.; Aslam, K.; Shabir, G.; Shah, S.M. Phytochemical profiling and antiviral activity of Ajuga bracteosa, Ajuga parviflora, Berberis lycium and Citrus lemon against Hepatitis C Virus. Microb. Pathog. 2018, 118, 154-158. [CrossRef]

20. Kayani, W.K.; Palazòn, J. Cusidò, R.M.; Mirza, B. The effect of rol genes on phytoecdysteroid biosynthesis in Ajuga bracteosa differs between transgenic plants and hairy roots. RSC Adv. 2016, 6, 22700-22708. [CrossRef]

21. Mauro, M.L.; Bettini, P.P. Agrobacterium rhizogenes rolB oncogene: An intriguing player for many roles. Plant Physiol. Biochem. 2021, 165, 10-18. [CrossRef]

22. Durak, T.; Depciuch, J. Effect of plant sample preparation and measuring methods on ATR-FTIR spectra results. Environ. Exp. Bot. 2020, 169, 103915. [CrossRef]

23. Liu, Y.; He, Z.; Uchimiya, M. Comparison of biochar formation from various agricultural by-products using FTIR spectroscopy. Mod. Appl. Sci. 2015, 9, 246. [CrossRef]

24. Bathoju, G.; Rao, K.; Giri, A. Production of sapogenins (stigmasterol and hecogenin) from genetically transformed hairy root cultures of Chlorophytum borivilianum (Safed musli). Plant Cell Tiss. Org. Cult. 2017, 131, 369-376. [CrossRef]

25. Fujimoto, Y.; Nakagawa, T.; Yamada, J.; Morisaki, M. Biosynthetic origin of C-26 and C-27 of the phytoecdysteroids cyasterone and 29-norcyasterone in Ajuga hairy roots. Chem. Commun. 1996, 2063-2064. [CrossRef]

26. Uozumi, N.; Ohtake, Y.; Nakashimada, Y.; Morikawa, Y.; Tanaka, N.; Kobayashi, T. Efficient regeneration from GUS-transformed Ajuga hairy root. J. Ferment. Bioeng. 1996, 81, 374-378. [CrossRef]

27. Kayani, W.K.; Palazòn, J.; Cusidò, R.M.; Mirza, B. Effect of $p$ Ri T-DNA genes and elicitation on morphology and phytoecdysteroid biosynthesis in Ajuga bracteosa hairy roots. RSC Adv. 2017, 7, 47945-47953. [CrossRef]

28. Cui, M.L.; Liu, C.; Piao, C.L.; Liu, C.L. A stable Agrobacterium rhizogenes-mediated transformation of cotton (Gossypium hirsutum L.) and plant regeneration from transformed hairy root via embryogenesis. Front. Plant Sci. 2020, 11, 604255. [CrossRef]

29. Dilshad, E.; Cusido, R.M.; Estrada, K.R.; Bonfill, M.; Mirza, B. Genetic transformation of Artemisia carvifolia Buch with rol genes enhances artemisinin accumulation. PLoS ONE 2015, 10, e0140266.

30. Arshad, W.; Haq, I.U.; Waheed, M.T.; Mysore, K.S.; Mirza, B. Agrobacterium-mediated transformation of tomato with rolB gene results in enhancement of fruit quality and foliar resistance against fungal pathogens. PLoS ONE 2014, 9, e96979. [CrossRef]

31. Schmülling, T.; Fladung, M.; Grossmann, K.; Schell, J. Hormonal content and sensitivity of transgenic tobacco and potato plants expressing single rol genes of Agrobacterium rhizogenes T-DNA. Plant J. 1993, 3, 371-382. [CrossRef]

32. Dilshad, E.; Zafar, S.; Ismail, H.; Waheed, M.T.; Cusido, R.M.; Palazon, J.; Mirza, B. Effect of rol genes on polyphenols biosynthesis in Artemisia annua and their effect on antioxidant and cytotoxic potential of the plant. Appl. Biochem. Biotechnol. 2016, 179, 1456-1468. [CrossRef]

33. Kiani, B.H.; Suberu, J.; Mirza, B. Cellular engineering of Artemisia annua and Artemisia dubia with the rolABC genes for enhanced production of potent anti-malarial drug artemisinin. Malar. J. 2016, 15, 252. [CrossRef]

34. Mauro, M.L.; Costantino, P.; Bettini, P.P. The never-ending story of rol genes: A century after. Plant Cell Tiss. Org. Cult. 2017, 131, 201-212. [CrossRef]

35. Rubnawaz, S.; Kayani, W.K.; Mahmood, R.; Mirza, B. Enhanced stress tolerance in transformed Ajuga bracteosa Wall. ex Benth regenerants by upregulated gene expression of metabolic pathways. Turk. J. Bot. 2020, 44, 410-426. [CrossRef]

36. Rubnawaz, S.; Akhtar, N.; Mahmood, R.; Khan, A.; Okla, M.K.; Alamri, S.A.; Alaraidh, I.A.; Alwasel, Y.A.; Mirza, B. Polyphenol rich Ajuga bracteosa transgenic regenerants display better pharmacological potential. Molecules 2021, 26, 4874. [CrossRef]

37. Ismail, H.; Dilshad, E.; Waheed, M.T.; Mirza, B. Transformation of lettuce with rolABC genes: Extracts show enhanced antioxidant, analgesic, anti-inflammatory, antidepressant, and anticoagulant activities in rats. Appl. Biochem. Biotechnol. 2017, 181, 1179-1198. [CrossRef]

38. Bulgakov, V.P.; Tchernoded, G.K.; Mischenko, N.P.; Shkryl, Y.N.; Glazunov, V.P.; Fedoreyev, S.A.; Zhuravlev, Y.N. Increase in anthraquinone content in Rubia cordifolia cells transformed by rol genes does not involve activation of the NADPH oxidase signaling pathway. Biochemistry (Moscow) 2003, 68, 795-801. [CrossRef] [PubMed]

39. Shkryl, Y.N.; Veremeichik, G.N.; Bulgakov, V.P.; Tchernoded, G.K.; Mischenko, N.P.; Fedoreyev, S.A.; Zhuravlev, Y.N. Individual and combined effects of the rolA, $B$, and $C$ genes on anthraquinone production in Rubia cordifolia transformed calli. Biotechnol. Bioeng. 2008, 100, 118-125. [CrossRef] [PubMed]

40. Bulgakov, V.P.; Khodakovskaya, M.V.; Labetskaya, N.V.; Chernoded, G.K.; Zhuravlev, Y.N. The impact of plant rolC oncogene on ginsenoside production by ginseng hairy root cultures. Phytochemistry 1998, 49, 1929-1934. [CrossRef]

41. Dubrovina, A.S.; Manyakhin, A.Y.; Zhuravlev, Y.N.; Kiselev, K.V. Resveratrol content and expression of phenylalanine ammonialyase and stilbene synthase genes in rolC transgenic cell cultures of Vitis amurensis. Appl. Microbiol. Biotechnol. 2010, 88, 727-736. [CrossRef] [PubMed]

42. Palazón, J.; Cusidó, R.M.; Roig, C.; Pinol, M.T. Expression of the rolC gene and nicotine production in transgenic roots and their regenerated plants. Plant Cell Rep. 1998, 17, 384-390.

43. Abbasi, M.S.; Tahir, M.A.; Meer, S. FTIR Spectroscopic study of aloe vera barbadensis Mill Buds. Asian J. Chem. Sci. 2020, 7 , 1-6. [CrossRef] 
44. dos Santos Grasel, F.; Ferrão, M.F.; Wolf, C.R. Development of methodology for identification the nature of the polyphenolic extracts by FTIR associated with multivariate analysis. Spectrochim. Acta A Mol. Biomol. Spectrosc. 2016, 153, 94-101. [CrossRef]

45. Donadu, M.G.; Peralta-Ruiz, Y.; Usai, D.; Maggio, F.; Molina-Hernandez, J.B.; Rizzo, D.; Bussu, F.; Rubino, S.; Zanetti, S.; Paparella, A.; et al. Colombian essential oil of Ruta graveolens against nosocomial antifungal resistant Candida strains. J. Fungus. 2021, 7,383. [CrossRef]

46. Langeveld, W.T.; Veldhuizen, E.J.; Burt, S.A. Synergy between essential oil components and antibiotics: A review. Crit. Rev. Microbiol. 2014, 40, 76-94. [CrossRef] [PubMed]

47. Brochot, A.; Guilbot, A.; Haddioui, L.; Roques, C. Antibacterial, antifungal, and antiviral effects of three essential oil blends. MicrobiologyOpen 2017, 6, e00459. [CrossRef] [PubMed]

48. Ganaie, H.A.; Ali, M.N.; Ganai, B.A.; Meraj, M.; Ahmad, M. Antibacterial activity of 14, 15-dihydroajugapitin and 8-oacetylharpagide isolated from Ajuga bracteosa Wall ex. Benth against human pathogenic bacteria. Microb. Pathog. 2017, 103, 114-118. [CrossRef] [PubMed]

49. Zahra, S.S.; Ahmed, M.; Qasim, M.; Gul, B.; Zia, M.; Mirza, B.; Haq, I.U. Polarity based characterization of biologically active extracts of Ajuga bracteosa Wall. ex Benth and RP-HPLC analysis. BMC Complement. Altern. Med. 2017, 17, 443. [CrossRef] [PubMed]

50. Rehman, N.U.; Begum, N.; Ali, L.; Al-Harrasi, A.; Abbas, G.; Ahmad, S.; Khan, A.L.; Shinwari, Z.K.; Hussain, J. Lipid peroxidation, antiglycation, cytotoxic, phytotoxic, antioxidant, antiplatelet and antimicrobial activities of Ajuga bracteosa against various pathogens. Pak. J. Bot. 2015, 47, 1195-1197.

51. Vohra, A.; Kaur, H. Chemical investigation of medicinal plant Ajuga bracteosa. J. Nat. Prod. Plant. Resour. 2011, 1, $37-45$.

52. Loganayaki, N.; Siddhuraju, P.; Manian, S. Antioxidant activity and free radical scavenging capacity of phenolic extracts from Helicteres isora L. and Ceiba pentandra L. J. Food Sci. Technol. 2013, 50, 687-695. [CrossRef] [PubMed]

53. Shabbir, M.; Khan, M.R.; Saeed, N. Assessment of phytochemicals, antioxidant, anti-lipid peroxidation and anti-hemolytic activity of extract and various fractions of Maytenus royleanus leaves. BMC Complement. Altern. Med. 2013, 13, 143. [CrossRef]

54. Imran, M.; Jan, H.; Faisal, S.; Shah, S.A.; Shah, S.; Khan, M.N.; Akbar, M.T.; Rizwan, M.; Jan, F.; Syed, S. In vitro examination of anti-parasitic, anti-Alzheimer, insecticidal and cytotoxic potential of Ajuga bracteosa Wallich leaves extracts. Saudi J. Biol. Sci. 2021, 28, 3031-3036. [CrossRef] [PubMed]

55. Solowey, E.; Lichtenstein, M.; Sallon, S.; Paavilainen, H.; Solowey, E.; Lorberboum-Galski, H. Evaluating medicinal plants for anticancer activity. Sci. World J. 2014, 2014, 721402. [CrossRef] [PubMed]

56. Pal, A.; Toppo, F.A.; Chaurasiya, P.K.; Singour, P.K.; Pawar, R.S. In vitro cytotoxicity study of methanolic fraction from Ajuga bracteosa wall ex. benth on MCF-7 breast adenocarcinoma and hep-2 larynx carcinoma cell lines. Pharmacogn. Res. $2014,6,87$.

57. Hussain, M.; Bibi, Y.; Raja, N.I.; Iqbal, M.; Aslam, S.; Tahir, N.; Imran, M.; Iftikhar, A. A review of therapeutic potential of Ajuga bracteosa: A critically endangered plant from Himalaya. J. Coast. Life Med. 2016, 4, 918-924.

58. Porebski, S.; Bailey, L.G.; Baum, B.R. Modification of a CTAB DNA extraction protocol for plants containing high polysaccharide and polyphenol components. Plant Mol. Biol. Rep. 1997, 15, 8-15. [CrossRef]

59. Sambrook, J.; Russell, D.W. Preparation of plasmid DNA by alkaline lysis with SDS: Minipreparation. Cold Spring Harb. Protoc. 2006, 2006, pdb.prot4084. [CrossRef] [PubMed]

60. Sarkar, S.; Jha, S. Effects associated with insertion of rol genes on morphogenic potential in explants derived from transgenic Bacopa monnieri (L.) Wettst. Plant Cell Tiss. Org. Cult. 2021, 12, 1-2.

61. Luz, A.C.; Pretti, I.R.; Batitucci, M. Comparison of RNA extraction methods for Passiflora edulis sims leaves. Rev. Bras. Frutic. 2016, 38, 226-232. [CrossRef]

62. Veremeichik, G.N.; Bulgakov, V.P.; Shkryl, Y.N.; Silantieva, S.A.; Makhazen, D.S.; Tchernoded, G.K.; Mischenko, N.P.; Fedoreyev, S.A.; Vasileva, E.A. Activation of anthraquinone biosynthesis in long-cultured callus culture of Rubia cordifolia transformed with the rolA plant oncogene. J. Biotechnol. 2019, 306, 38-46. [CrossRef]

63. Meziti, H.; Bouriche, H.; Kada, S.; Demirtas, I.; Kizil, M.; Senator, A.; Garrido, G. Phytochemical analysis, and antioxidant, anti-hemolytic and genoprotective effects of Quercus ilex L. and Pinus halepensis Mill. methanolic extracts. J. Pharm. Pharmacogn. Res. 2019, 7, 260-272.

64. McLaughlin, J.L.; Rogers, L.L.; Anderson, J.E. The use of biological assays to evaluate botanicals. Drug Inf. J. 1998, 32, 513-524. [CrossRef]

65. Bhukya, B.R.; Yellu, N.R. Evaluation of anticancer activity of methanolic extract of Hiptage benghalensis (L.) Kurz on cancer cell lines. Pharmacogn. Res. 2018, 10, 309-313.

66. Ahmad, B.; Islam, A.; Khan, A.; Khan, M.A.; ul Haq, I.; Jafri, L.; Ahmad, M.; Mehwish, S.; Khan, A.; Ullah, N. Comprehensive investigations on anti-leishmanial potentials of Euphorbia wallichii root extract and its effects on membrane permeability and apoptosis. Comp. Immunol. Microbiol. Infect. Dis. 2019, 64, 138-145. [CrossRef] [PubMed] 